Volume, 14, número, 1, ano, 2018.

\title{
GRAMSCI EDUCADOR: UMA LEITURA DAS CARTAS A DELIO E GIULIANO (1929-1937)
}

\author{
Jarbas Maurício Gomes ${ }^{1}$
}

\begin{abstract}
RESUMO Este texto analisa o pensamento educacional do intelectual italiano Antonio Gramsci (1891-1937) e o teor educativo de um conjunto de 43 Cartas redigidas por Gramsci entre 1929 e 1937 e destinadas aos seus filhos Delio e Giuliano. As reflexões que Gramsci desenvolveu com os filhos nas Cartas do cárcere retomam as notas e os temas dos Cadernos do Cárcere, em especial a sua concepção de educação e de escola unitária. Nas cartas aos filhos, Gramsci evidenciou o papel formativo da disciplina de estudos e destacou a importância e o papel de uma educação voltado ao desenvolvimento físico e intelectual do indivíduo por meio de uma formação de cultura geral.
\end{abstract}

Palavras-chave: Educação. Antonio Gramsci. Cartas do Cárcere.

\section{GRAMSCI EDUCATOR: A LECTURE OF THE LETTERS SENDS TO DELIO AND GIULIANO (1929-1937)}

\begin{abstract}
This paper analyzes the educational thought of Italian intellectual Antonio Gramsci (1981-1937) and the educative content a set of 43 letters written by Gramsci between 1929 and 1937 and addressed for their children Delio and Giuliano. The reflections that Gramsci developed with children in Letters from Prison resume notes and themes of the Prison Notebooks, in particular its conception of education and unitary school. In letters to the children, Gramsci evidenced the formative role of discipline studies and highlighted the importance of an education focused on the physical and intellectual development of the individual by means of a formation of general culture.
\end{abstract}

Key-words: Education. Antonio Gramsci. Letters from Prison.

\section{INTRODUÇÃO}

O presente texto é resultado de um estudo exploratório e bibliográfico que teve como objeto o pensamento educacional do italiano Antonio Gramsci (1891-1937) e analisou o conteúdo de um conjunto de 43 cartas do período carcerário, escritas entre 1929 e 1937 e destinadas aos seus filhos Delio e Giuliano. Este conjunto de cartas, pouco lido entre os pesquisadores brasileiros, permite observar uma práxis educativa que remete às notas dos

\footnotetext{
1 Doutor em Educação pela UFSCar, Mestre em Educação pela UEM (2012), Especialista em Pesquisa Educacional pela UEM (2009), Graduado em Filosofia pela Universidade Estadual do Oeste do Paraná (2003). Professor do Instituto Federal de Educação, Ciência e Tecnologia de Alagoas - Campus Penedo.
} 
Volume, 14, número, 1, ano, 2018.

Cadernos do Cárcere ${ }^{2}$. Quando Gramsci intensificou a correspondência com os filhos já havia produzido grande parte das notas dos Cadernos e amadurecido suas reflexões e críticas à educação e à estratégia revolucionária empregada na década de 1920.

A concepção gramsciana de educação guarda relação com sua militância no movimento operário e com suas teorizações sobre política. Consequentemente, as ideias educacionais remetem aos processos formativos do proletariado e das novas gerações dos grupos sociais subalternos. Por isso, quando da análise do pensamento educacional gramsciano é pertinente considerar dois conceitos desenvolvidos nos Cadernos: americanismo e conformismo ${ }^{3}$. O primeiro denomina o modelo econômico-cultural de sociedade a partir da qual Gramsci elaborou suas ideias. Ou seja, uma economia fundada na produção industrial e para qual o trabalhador deveria ser educado. $\mathrm{O}$ segundo expressa o resultado esperado da ação educativa de preparação para o trabalho, ou seja, a conformação dos indivíduos ao modelo econômico-cultural hegemônico, um meio de inserção e permanência das classes subalternas na sociedade industrial.

Os conceitos de americanismo e conformismo conferem materialidade e historicidade ao pensamento gramsciano ao situá-lo no contexto histórico do início do século XX. A partir da dialética entre um modelo econômico-cultural de sociedade e os anseios do proletariado, estes conceitos permitem analisar a educação das novas gerações em um momento histórico no qual o resultado de toda a ação educativa era a conformação do indivíduo à sociedade industrial, independente se esta conformação liberta ou se torna causa de alienação. Gramsci, no entanto, pensou o conformismo em sua face libertadora e emancipatória, na qual a educação tem o papel de preparar o homem para que se adapte à sociedade, conformando-se a ela e moldando-a de acordo com uma concepção de mundo.

Perspectiva evidente ao final do Caderno 12 quando Gramsci define no $§ 3$ a forma de ser do novo intelectual: alguém que possui o domínio dos fundamentos da técnica e do filosofar e por isso é capaz de dominar a tecnologia e se especializar tecnicamente e de atuar

\footnotetext{
${ }^{2}$ A obra de Gramsci é tradicionalmente dividida dois conjuntos de textos. Os textos pré-carcerários ou políticos, anteriores a sua prisão em 1926, e os textos carcerários, escritos após no período em que esteve preso entre os anos de 1926 e 1937. Os escritos do período carcerário têm sido organizados em dois grupos, as Cartas do Cárcere e os textos dos Cadernos do Cárcere. Os Cadernos são um conjunto de anotações redigidas em 33 cadernos escolares fornecidos pela direção do Cárcere após a concessão de uma autorização que em fevereiro de 1929 permitia que Gramsci tivesse e em sua cela o material necessário para escrever.

${ }^{3}$ Os conceitos de americanismo e conformismo foram explorados por Mario Alighiero Manacorda (2008) em O princípio educativo em Gramsci: americanismo e conformismo, obra datada de 1975.
} 
Volume, 14, número, 1, ano, 2018.

como dirigente. Por isso, o intelectual sardo defendeu uma educação capaz de fornecer os elementos necessários ao domínio dos mecanismos de participação e organização do Estado, tanto no que se refere à organização da produção quanto no âmbito das relações políticas, atuando na organização da sociedade, para transformá-la de acordo com as necessidades.

Para a formação deste novo intelectual, a educação deve ser pensada como a ação de formação do homem atual ao contexto histórico, isto é, um homem do tempo presente, capaz de se inserir na sociedade compondo o homem-coletivo sem perder a personalidade e a originalidade criativa. A educação, portanto, como apresentado no $\S 121$ do Caderno 1, deve conceder a ele o domínio de sua própria natureza por meio da disciplina e do desenvolvimento intelectual, propiciando as condições para que se adapte e atue sobre a organização política e econômica da sociedade ao mesmo tempo em que possa transformá-la.

Nas cartas que escreveu aos filhos, Gramsci não desenvolveu uma reflexão teórica sobre educação e não se ocupou em debater as características da educação escolar dos filhos ou dos sobrinhos, tema presente nas cartas que enviou aos irmãos, à esposa e à cunhada Tatiana ${ }^{4}$. Nas cartas aos filhos, Gramsci desenvolveu aquilo que pode ser considerado um vislumbre sobre a práxis educativa teorizada nos Cadernos, o ato de formação do homem atual. A preocupação de Gramsci com o desenvolvimento integral dos seus filhos remete a uma concepção de educação como formação integral do homem e que visa tanto o desenvolvimento das habilidades físico-motoras como das habilidades intelectuais. Princípio educativo que é central em todo o pensamento educacional gramsciano e que permeia os debates sobre espontaneísmo e coerção, direção e autoridade entre outros.

Nas cartas aos filhos, Gramsci não se ocupou destes temas, mas se esforçou em transmitir aos seus filhos o método e a disciplina de estudos, reforçando a perspectiva de que é pela unidade entre teoria e prática que se efetiva a possibilidade de dotar as novas gerações com o instrumental necessário para a análise e interpretação da realidade e para a elaboração da filosofia da práxis e de uma concepção de mundo voltada para a transformação da sociedade. Por isso, este texto limita-se a apresentar a unidade entre teoria e prática e

\footnotetext{
${ }^{4}$ A relação teórica entre temas educacionais dos cadernos e das cartas foi objeto de análise em diferentes textos e está presente em obras clássicas da interpretação de Gramsci, como os livros O princípio educativo em Gramsci de Mario Alighiero Manacorda (2008) e A escola de Gramsci de Paolo Nosella, dentre outros. Além desses, podem ser mencionados os textos A educação de Edmea: concepções educativas de Gramsci nas Cartas do Cárcere de Rosemary Dore Heijmans e Alessandro de Melo (2013) e O princípio educativo nas cartas do Cárcere de Antonio Gramsci de Ana Priscila Cardoso Zanedim e Alessandro de Melo (2016).
} 
REVISTA ELETRÔNICA

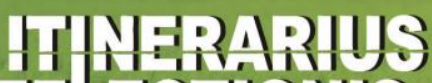
RAFliscrilonts

Volume, 14, número, 1, ano, 2018.

evidenciar algumas relações entre as ideias gramscianas sobre educação sistematizadas nos

Cadernos e a práxis educativa desenvolvida nas cartas que enviou a Delio e Giuliano.

\section{AS EDIÇÕES DAS CARTAS DO CÁRCERE E AS CARTAS AOS FILHOS}

Atualmente são conhecidas 494 cartas escritas por Gramsci no período do cárcere, das quais 478 são direcionadas aos familiares e amigos e 16 são petições e cartas destinadas a Mussolini e as autoridades carcerárias. A primeira edição das cartas foi organizada por Palmiro Togliatti e publicada na Itália pela editora Einaudi em 1947, sob o título de Lettere dal Carcere. Era uma coletânea de 218 cartas apresentadas parcialmente com cortes e supressões. Naquele mesmo ano, a edição ganhou destaque quando foi agraciada com o Prêmio de Literatura Viareggio. Em 1965 foi publicada pela mesma editora uma segunda edição organizada por Elsa Fubini e Sérgio Caprioglio e que apresentava sem cortes ou supressões as 428 cartas até então conhecidas (VACCA, 1991).

Em 1996 Antonio A. Santucci organizou uma edição mais completa, contendo as 494 cartas atualmente conhecidas. Por fim, em 2009 começou a ser publicado na Itália o Epistolário de Gramsci como parte da Edizione Nazionale. O projeto editorial do Epistolário compreende ao todo nove volumes, com cartas dos períodos carcerário e pré-carcerário. Este é ao projeto mais completo já proposto eorganizado porque contém cartas enviadas e recebidas. Até o momento foram publicados dois volumes, um em 2009 e outro em 2011 e que apresentam, respectivamente, as cartas de 1906-1922 e as de janeiro a novembro de 1923.

No Brasil foram publicadas várias edições das Cartas do Cárcere, duas são as mais conhecidas. A primeira foi organizada e traduzida por Noêmio Spínola e publicada pela Civilização Brasileira em 1966. Ela continha 233 cartas selecionadas a partir das edições italianas conhecidas até então, a de Togliatti e a de Elsa Fubini e Sérgio Caprioglio. Em 2005 a Civilização Brasileira publicou uma nova edição composta de dois volumes organizados por Carlos Nelson Coutinho, Luiz Sérgio Henriques e Marco Aurélio Nogueira. Nela são apresentadas as 478 cartas a as 16 petições de Gramsci, 16 cartas recebidas por ele no período carcerário e uma petição enviada a Mussolini por Giuseppina Marcias Gramsci, mãe de Gramsci (HENRIQUES, 2005). 


\section{HyHFAius RBFliscilloils \\ REVISTAELETRÔNICA \\ GRADUAÇÃ O/PÓS-GRADUAÇÃO EM EDUCAÇÃ O \\ UFG / REJ}

ISSN $1807-9342$

Volume, 14, número, 1, ano, 2018.

Em 2007, por ocasião das homenagens ao septuagésimo ano do falecimento de

Gramsci, a Fundação da Câmara dos Deputados da Itália publicou uma edição comemorativa apresentando as cartas enviadas a Delio e Giuliano. Intitulada Antonio Gramsci ai figli -

Lettere dal carcere (Antonio Gramsci aos filhos - Cartas do cárcere, sem tradução para o português) a antologia é composta de 42 cartas. Atualmente, tem-se conhecimento de que Gramsci escreveu 43 cartas aos filhos entre 1929 e 1937 e todas estão publicadas na nova edição brasileira que, em relação à edição comemorativa da Fundação da Câmara dos Deputados, apresenta a carta 435 destinada a Delio no ano de $1936^{5}$.

As cartas eram remetidas em anexo à correspondência destinada à sua esposa Giulia e por isso algumas não possuem datação, condição que dificulta determinar com precisão quando foram escritas ${ }^{6}$. Gramsci escrevia aos filhos em separado, mas em janeiro de 1933 escreveu a única carta destinada a ambos. Das 43 cartas conhecidas, Delio foi destinatário de 23 e Giuliano de 19 e apenas 12 cartas estão datadas com precisão (Quadro 1).

Quadro 1 - Cartas de Gramsci aos filhos (1929-1937). Numeração de acordo com a Edição Brasileira das Cartas do Cárcere de 2005.

\begin{tabular}{|c|c|c|}
\hline Ano & Cartas a Delio & Cartas a Giuliano \\
\hline 1929 & $151-20$ de maio & \\
\hline 1932 & $\begin{array}{l}287-22 \text { fevereiro } \\
341-10 \text { Outubro }\end{array}$ & 346 - 24 de Outubro \\
\hline \multirow[b]{2}{*}{1933} & \multicolumn{2}{|c|}{367 - 16 de Janeiro } \\
\hline & $\begin{array}{l}385 \text { - } 10 \text { de Abril } \\
397 \text { - } 11 \text { de Junho }\end{array}$ & \\
\hline 1935 & 427 - 08 de Abril & 429 - Sem data \\
\hline 1936 & $\begin{array}{l}435 \text { - Sem data } \\
437 \text { - } 16 \text { de Julho } \\
439 \text { - Sem data } \\
440 \text { - Julho } \\
441 \text { - Agosto } \\
447 \text { - Novembro } \\
449 \text { - Dezembro } \\
452 \text { - Sem data }\end{array}$ & $\begin{array}{l}434 \text { - } 25 \text { de janeiro } \\
446 \text { - } 24 \text { de Novembro } \\
451 \text { - Sem data } \\
454 \text { - Sem data }\end{array}$ \\
\hline
\end{tabular}

\footnotetext{
5 As menções e citações das Cartas do Cárcere remetem à numeração da Edição Brasileira de 2005, organizada por Carlos Nelson Coutinho, Luis Sérgio Henriques e Marco Aurélio Nogueira. As citações indicam o número da carta, o volume e a página (Ex: CtC 1, v. 1, p. 73).

${ }^{6}$ A Edição Brasileira das Cartas do Cárcere, publicada em 2005, reproduz a organização das edições italianas e apresenta as cartas sem datação ao final da edição.
} 


\section{HyHAinius

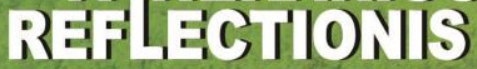

Volume, 14, número, 1, ano, 2018.

\begin{tabular}{|c|c|c|}
\hline 1937 & $\begin{array}{l}459 \text { - Sem data } \\
462 \text { - Sem data } \\
464 \text { - Sem data } \\
465 \text { - Sem data } \\
466 \text { - Sem data } \\
468 \text { - Sem data } \\
476 \text { - Sem data } \\
477 \text { - Sem data } \\
478 \text { - Sem data }\end{array}$ & $\begin{array}{l}457 \text { - } 23 \text { de Janeiro } \\
458 \text { - Sem data } \\
460 \text { - Sem data } \\
461 \text { - Sem data } \\
463 \text { - Sem data } \\
467 \text { - Sem data } \\
469 \text { - Sem data } \\
470 \text { - Sem data } \\
471 \text { - Sem data } \\
472 \text { - Sem data } \\
473 \text { - Sem data } \\
474 \text { - Sem data } \\
475 \text { - Sem data }\end{array}$ \\
\hline
\end{tabular}

Fonte: próprio autor, com base na Edição Brasileira de 2005.

Em decorrência de seu estado de saúde, em dezembro de 1933 Gramsci foi transferido da Casa Penal Especial de Turi na província de Bari para uma clínica na cidade de Fórmia. Neste período, encontrava-se cansado e recebia visitas semanais de Tatiana que lhe trazia notícias de Giulia, dos meninos e de seus familiares e os informava sobre a saúde de Gramsci (FIORI, 1979). Por isso, entre junho de 1933 e abril de 1935 não escreveu aos filhos. Provavelmente não sentia a necessidade de escrever, como relatou na única carta escrita em 1934 e destinada a sua mãe, Giuseppina Gramsci (1861-1932) ${ }^{7}$ :

Tatiana tem informado Teresina sobre minhas novas condições de vida, que, mesmo não sendo das melhores, certamente não podem ser comparadas às de um ano atrás. Não lhes escrevi até agora porque tenho estado sempre um pouco desnorteado e também porque sabia que Tatiana, que vem me visitar todos os domingos, os mantém informados (CtC 426, v. 2, p. 385).

Em 1935 Gramsci retomou a correspondência com Giulia e os meninos e, a partir de então, mesmo diante de suas difíceis condições de saúde buscou mantê-la com certa periodicidade. Em 25 de outubro de 1935 adquiriu a liberdade condicional, passou a receber visitas e a passear na cidade, mas continuava na clínica em Fórmia sob vigilância policial (FIORI, 1979). Em 1936 continuou a escrever para a esposa e os filhos que estavam em Moscou. Das cartas escritas em 1937, a maioria foi destina aos filhos e muitas consistem em pequenos bilhetes, poucas linhas nas quais fez muitos questionamentos sobre gostos, saúde,

\footnotetext{
${ }^{7}$ Deve-se ressaltar que Giuseppina havia falecido em 1932 e que o irmão Carlo e a cunhada Tatiana não tiveram a coragem de lhe contar o ocorrido. Situações como essa acabava por desgastar ainda mais o estado emocional de Gramsci, que em muitos casos se sentia traído por seus familiares (FIORI, 1979).
} 
Volume, 14, número, 1, ano, 2018.

desenvolvimento físico e intelectual e procurou transmitir seu carinho e afeto e, sobretudo, solicitava que os filhos lhe escrevessem.

\title{
3. EDUCAR PARA O DESENVOLVIMENTO FÍSICO E INTELECTUAL: A DISCIPLINA DE ESTUDOS
}

A primeira carta destinada a Delio sintetiza o desejo paterno de conhecer e compartilhar a vida do filho e Gramsci o convidava a estabelecer relações ainda que por correspondência. Nas breves linhas que escrevia, Gramsci procurava transmitir aos filhos a sua experiência e seu legado cultural e buscou demonstrar que é possível superar os limites característicos da natureza humana, enfatizando que para isso é necessário racionalizar sobre a própria existência, reconhecer os limites individuais e buscar estratégias para a sua superação.

\begin{abstract}
Soube que você vai à escola, tem um metro e oito centímetros de altura e pesa dezoito quilos. Assim, acho que já é muito grande e em pouco tempo irá me escrever cartas. Enquanto espero por isso, hoje mesmo você já pode fazer a mamãe escrever cartas, ditadas por você, tal como me fazia escrever, em Roma [...]. Assim, você vai me dizer se gosta dos outros meninos na escola, o que é que aprende e como gosta de brincar. Sei que constrói aeroplanos e trens e participa ativamente da industrialização do país, mas será que esses aeroplanos voam de verdade e estes trens correm? [...] (CtC 151, v. 1, p. 342).
\end{abstract}

Conformismo e americanismo são os conceitos chave para interpretação da carta. Ainda que temas fundamentais e indispensáveis para a compreensão do pensamento educacional de Gramsci - como hegemonia, bloco histórico, intelectuais, jacobinismo e outros - tratados nos Cadernos do Cárcere não sejam citados eles elucidam o trabalho educativo realizado por ele. Gramsci não deixou escapar a dialética das relações materiais nas quais Delio e Giuliano estavam inseridos, ele as explorou partindo da noção de que toda ação educacional promove o conformismo. Por isso, procurou expor a dimensão exata da inserção de seus filhos na sociedade de seu tempo, expondo as contradições presentes no sistema educacional que não tinha como fim a emancipação humana, mas a formação profissional.

A carta 151 apresenta uma concepção de educação que valoriza a cultura intelectual de cunho escolar, a partir da qual os jovens aprendizes, no caso seus filhos, tornar-se-iam capazes de pensar sobre a própria vida, organizar, registrar e transmitir ideias através da 
Volume, 14, número, 1, ano, 2018.

escrita. Gramsci explorou a noção de trabalho como princípio educativo, desenvolvida no Caderno 12, e contrapôs essa concepção à tendência política da época, voltada à profissionalização dos jovens para o atendimento das demandas da sociedade industrial. A crítica gramsciana ao sistema escolar de seu tempo é sutil e tem em conta as noções de americanismo e conformismo, evidenciadas na identificação da inserção social de Delio na sociedade industrial, pois o menino "participava ativamente" no "desenvolvimento do país".

A indagação é o elemento filosófico-educativo da carta. Por ela Gramsci almeja desconstruir as certezas e evidenciar as contradições existentes na constituição da sociedade industrial. Será que a participação do sujeito na sociedade é real? Gramsci explorou o tema no Caderno 22 ao analisar a relação entre a educação e a manutenção da hegemonia na sociedade industrial evidenciando que o subalterno, uma vez preparado para o trabalho, é inserido no mundo da produção e, incapaz de superar essa condição e motivado pelo engodo de que participa da esfera econômica, é conduzido à conformação. Isto é, o sujeito é condicionado a se resignar e se contentar com a pequena parte do capital que lhe é ofertada.

Para conduzir e estimular o filho na conquista da autonomia e da superação da conformação em uma cultura de tipo americano limitada à profissionalização, Gramsci propôs a Delio um problema: escrever cartas ao seu pai. Qual seria a reação do menino frente ao desafio que lhe era posto? Gramsci queria conhecê-lo e solicitou que Giulia observasse e narrasse as reações do filho diante da leitura da $\operatorname{carta}^{8}$. Consciente de que o filho ainda não era capaz escrever devido aos limites motores e intelectuais próprios da idade, que ele não tinha domínio da escrita e da organização lógica das ideias, Gramsci apresentou a solução para o problema na própria carta: ditar o texto. A solução valorizava a experiência subjetiva, evocada por meio da rememoração de experiências concretas e pela materialidade histórica de uma experiência real vivenciada por eles em Roma num episódio no qual Gramsci escrevia textos e desenhava os animais que Delio descrevia (FIORI, 1979).

Se de um lado estimulava o desenvolvimento intelectual do filho, por outro lhe ensinava que firmar uma parceria com a mãe colocava em seu poder habilidades físicas e intelectuais que não dominava. O tema aparece no Caderno 12, nas análises sobre a relação

\footnotetext{
${ }^{8} \mathrm{Na}$ última frase da carta 150, de 20 de maio de 1929 junto a qual enviou o bilhete a Delio, Gramsci escreveu: "Cara Giulia, Escreva-me sobre os comentários de Delio à carta que vou escrever a ele; abraços carinhosos" (CtC 150, v. 1, p. 341).
} 


\section{REVISTA ELETROONICA \\ GRADUAÇÃO/PÓS-GRADUAÇÃO EM EDUCAÇÃO \\ UFG/REJ}

ISSN $1807-9342$

Volume, 14, número, 1, ano, 2018.

entre o grupo hegemônico e os intelectuais ${ }^{9}$. Ao estabelecer a distinção entre intelectuais orgânicos e tradicionais, demonstrou como o grupo hegemônico agregava em torno de si grupos de intelectuais cujo fim era desempenhar as atividades necessárias à manutenção de sua hegemonia. Contrário ao espontaneísmo, Gramsci opta por apresentar a Delio meios para a superação de limitações, incentiva e orienta a ação do menino para que este alcance o fim desejado. Ainda que a idade não permitisse a Delio compreender a profundidade das palavras que seu pai, elas são dotadas de uma práxis educativa voltada ao autoconhecimento da própria natureza (natureza humana) e no desenvolvimento das capacidades física e intelectual.

Essa perspectiva de educação, voltada para o desenvolvimento das capacidades físicas e intelectuais dos indivíduos pelo domínio da própria natureza, foi desenvolvida por Gramsci no $§ 123$ do Caderno 1, na qual indicou que “[...] a educação é uma luta contra os instintos ligados às funções biológicas elementares, uma luta contra a natureza, a fim de dominá-la e de criar o homem 'atual' à sua época [...]” (QC 1, § 123. p. 114) ${ }^{10}$. Para Gramsci, abandonar a criança ao próprio desenvolvimento não lograria o efeito desejado sendo necessário educá-la, isto é, auxiliá-la a desenvolver a disciplina e treiná-la para exercer o domínio sobre sua natureza. Esse era o fundamento da Era Moderna onde o homem em suas relações com a natureza se tornou seu senhor e a colocou a sua disposição.

Pela rememoração de suas experiências da infância e juventude Gramsci procurou dar materialidade para as experiências que os filhos estavam vivendo, assim escreveu a Delio: “[...] Numa outra vez, vou lhe escrever sobre as danças das lebres e outros animais: quero lhe contar coisas que vi e ouvi quando era menino [...]" (CtC 287, v. 2, p. 164). Com estas narrativas ele apresenta aos filhos a noção de que o universo que eles começavam conhecer, embora lhes parecesse novo, já havia sido explorado e sofrido a interferência de outros homens, e dentre eles, de seu próprio pai.

Neste conjunto de cartas a relação entre o presente e o passado, entre as experiências vivenciadas por Delio e Giuliano e as experiências históricas vivenciadas pela humanidade é marcante. Ao tomar ciência de que Delio havia conhecido o oceano, na carta 342 de outubro de 1932 interrogou-o sobre a experiência. Em 1935, quando Giuliano conheceu o oceano, fez

\footnotetext{
${ }^{9}$ Os Cadernos do Cárcere serão citados, com tradução livre para o português e a partir da Edição Critica do Instituto Gramsci, pela abreviação QC, seguida do número do parágrafo e da página (Ex: QC 1, §. 1, p. 1).

${ }^{10} \mathrm{O} \S 123$ do Caderno 1 está disponível em português em duas edições: 1) no volume 2 da Edição Brasileira dos Cadernos do Cárcere sub-intitulado de Os intelectuais. O Princípio Educativo. Jornalismo (GRAMSCI, 2006) - mais recomendado - e; 2) na Coletânea Os intelectuais e a Organização da Cultura (GRAMSCI, 1982).
} 
Volume, 14, número, 1, ano, 2018.

reflexão semelhante na carta 429. Em ambas as situações procurou dar historicidade às experiências dos filhos e os instigou a relatá-las, pedindo que narrassem suas impressões em detalhes. Pediu a Delio que descrevesse as belezas que tinha visto em sua visita à praia e, com uma série de questões, convidou Giuliano a escrever sobre o tema.

Você [Giuliano] viu o mar pela primeira vez. Escreva-me algumas impressões suas. Bebeu muita água salgada quando foi se banhar? Aprendeu a nadar? Pegou peixinhos vivos ou caranguejos? Eu vi alguns meninos que apanhavam peixinhos no mar com um tijolo vazado (virado para cima); eles encheram de peixe um pequeno balde (CtC 429, v. 2, p. 386).

Aproveitando as situações cotidianas vivenciadas pelos filhos, pelo exercício da rememoração procurava lhes disciplinar a observação e pela redação das cartas os incentivava a organizar e sistematizar suas ideias. De acordo com a concepção gramsciana de educação apresentada no Caderno $1 \S 127$, dominar a inquietude juvenil se apresenta como um exercício da responsabilidade e uma oportunidade para o domínio dos instintos naturais, condição necessária para o desenvolvimento da disciplina de estudos e de habilidades intelectuais como a observação, análise, descrição e organização lógica do pensamento. $\mathrm{O}$ exercício da escrita necessário na comunicação entre Gramsci e os filhos, apresentava-se como uma ferramenta de domínio da natureza, uma habilidade que requeria paciência e dedicação no domínio das habilidades motoras e intelectuais presentes no ato de escrever.

Embora o termo disciplina não apareça nas cartas enviadas aos filhos, ele compõe a práxis educativa desenvolvida por meio delas e se encontra presente nas ideias e noções que eram transmitidas. Um exemplo disso está na carta 434 que escreveu para Giuliano: “[...] tenho certeza de que vai me escrever sem interrupção e me manter informado sobre a sua vida" (CtC 434, v. 1, p. 396). Dadas as condições de sua relação com os filhos, escrever cartas era uma estratégia educativa que tinha dupla função. Além de acalentar a saudade e a falta que sentia dos filhos, visava desenvolver neles a disciplina de estudos. A busca pela disciplina se torna evidente na carta 437 de 16 de junho de 1936. Nela, Gramsci chamou a atenção de Delio sobre o que escrevia e fez uma crítica que fornecia ao menino elementos para que desenvolvesse a autonomia e a consciência sobre seu próprio pensamento e o que escrevia. 
Volume, 14, número, 1, ano, 2018.

[...] Eu acredito que você tem bastante tempo para escrever de modo mais extenso e mais interessante; não há necessidade nenhuma de escrever no último momento, às pressas, correndo, antes de ir brincar. Você não acha? E, também acredito, você não gostaria que seu pai o julgasse por seus bilhetinhos, como um bobinho que só se interessa pelo destino de seu pequeno papagaio e diz estar lendo um livro qualquer [...] (CtC 437, v. 1, p. 398).

Delio estava para completar doze anos e Gramsci transferia para ele a avaliação de suas escolhas e ações. Ele se adiantava ao conformismo dos filhos perante a sociedade na qual estavam inseridos e antevia que era prudente incentivá-los a pensar sobre suas ações e, como um mestre, apresentava-lhes uma valiosa lição:

[...] Acredito que uma das cosias mais difíceis, em sua idade, é ficar sentado diante de uma escrivaninha para botar ordem nos próprios pensamentos (ou até para pensar) e escrevê-los com certa elegância; talvez seja uma aprendizagem mais difícil do que a de um operário que queira adquirir uma qualificação profissional e deva começar exatamente em sua idade (CtC 437, v. 2, p. 398-399).

Deve-se atentar para o fato de que Gramsci estava preocupado com a questão da aquisição da disciplina de estudos, tanto em seu aspecto físico quanto no seu aspecto intelectual. As indicações são orientações voltadas ao desenvolvimento ou apropriação das condições necessárias para que o indivíduo desenvolva a sua intelectualidade. Por ser um trabalho educativo de longa data, a aquisição da disciplina de estudos deve ser iniciada na infância para que as crianças a adquiram gradualmente, respeitando as fases de seu desenvolvimento físico e intelectual. Neste sentido, a escola, que é uma fração na vida do aluno (Caderno 12), figura como um instrumento educativo que propicia à criança e ao jovem o domínio da vontade e o desenvolvimento da disciplina de estudos.

A questão da disciplina de estudos é um tema central na compreensão do pensamento educacional gramsciano e da concepção de escola unitária. Deve-se ressaltar que ao tratar da educação escolar das crianças e dos jovens, e ao expor a concepção de escola unitária, Gramsci considerava que na formação escolar nos níveis elementar e médio, que corresponde à atual Educação Básica brasileira, os esforços educativos deveriam estar voltados à formação cultural e não a qualificação profissional. Talvez este seja o mote de suas considerações a Delio quando trata da diferença entre a formação intelectual e a qualificação profissional. 
Volume, 14, número, 1, ano, 2018.

Para Gramsci, o resultado do processo educativo é a tomada de consciência do indivíduo sobre si mesmo e o desenvolvimento das habilidades físicas e intelectuais, como indicou na Carta 437. Para ele, pensar e organizar o pensamento eram atividades complexas e difíceis quando comparadas a qualificação profissional de um operário. Ele não queria desmerecer a qualificação profissional, mas considerava que essa modalidade de formação deveria ocorrer em um momento distinto e posterior ao desenvolvimento intelectual ${ }^{11}$. Com isso, defende que ao vivenciar uma formação educativa de longa data e ao adquirir a disciplina de estudos, o jovem não teria dificuldade para se qualificar profissionalmente, pois o desenvolvimento físico e intelectual são condições necessárias à profissionalização.

Portanto, na idade de Delio, por volta dos doze anos, deveria ter lugar uma formação escolar desinteressada na profissionalização e voltada ao domínio da cultura geral de cunho filosófico e científico. Gramsci defendeu uma educação que, embora fundamentada no trabalho como princípio educativo, não estivesse preocupada em conduzir o jovem estudante ao conformismo característico da sociedade industrial, o que ocorreria caso a criança ou o adolescente fossem submetidos a uma formação profissional que fosse simultânea ou substituísse a escola média, como ocorreu na Itália na década de 1920.

No Caderno 12, ao analisar a organização escolar italiana decorrente da reforma educacional de 1921, Gramsci destacou que a estrutura escolar daquela época originava dois tipos de escolas, uma destinada aos filhos dos dirigentes e outra aos filhos dos proletários. Enquanto aos filhos dos dirigentes a escola oferecida uma formação de cultura geral, o que permitia o acesso à universidade e aos níveis mais elevados da formação científica, filosófica e cultural, aos filhos das classes subalternas era ofertada uma escola de formação profissional, destinada a preparação e inserção imediata dos jovens filhos dos trabalhadores no mundo da produção industrial (ARNAUT DE TOLEDO; GOMES, 2013).

Para seus filhos e para todas as crianças e jovens, inclusive aqueles das classes subalternas, Gramsci desejava uma escola de formação geral, a mesma que na Itália era

\footnotetext{
${ }^{11}$ Estes temas foram tratados no Caderno 12 quando expôs a concepção de escola unitária e o trabalho como princípio educativo. Gramsci defendia que a formação profissional deveria ocorrer em uma etapa posterior a formação intelectual dos estudantes e que a formação intelectual, promovida até o estudante atingir os 16 anos de idade, deveria acontecer em uma "[...] escola única inicial de cultura geral, humanista, formativa, que equilibre equanimemente o desenvolvimento da capacidade de trabalhar manualmente (tecnicamente, industrialmente) e o desenvolvimento das capacidades de trabalho intelectual. Deste tipo de escola única, através de repetidas experiências de orientação profissional, passar-se-á a uma das escolas especializadas ou ao trabalho produtivo. [...]" (QC 12, § 1. p. 1531).
} 
REVISTA ELETRÔNICA

GRADUAÇÃO /PÓS-GRADUAÇÃO EM EDUCAÇÃ O

UFG / REJ

ISSN $1807-9342$

Volume, 14, número, 1, ano, 2018.

ofertada aos filhos da classe dirigente. Essa proposta está clara no Caderno 12 na formulação da concepção de escola unitária, uma escola de cultura geral que habilitaria os estudantes para atuarem tanto na esfera da sociedade política como da sociedade civil, seja na elaboração da filosofia da práxis e das ideologias, seja na organização e produção material da vida ${ }^{12}$. De cunho intelectual e manual, a escola unitária visa o desenvolvimento das habilidades físicas e intelectuais dos estudantes e, por meio do exercício da disciplina, promoveria o domínio da natureza humana, para, só então, pela formação profissional, participar ativamente da esfera econômica da sociedade.

\section{EDUCAR PARA A EMANCIPAÇÃO HUMANA: O DOMÍNIO DO MÉTODO}

Comprometido com a emancipação humana, Gramsci pautou-se por uma práxis educativa que privilegiasse a formação integral e o ensino da cultura geral. Perspectiva educativa que está para além da transmissão de conteúdos e se constitui como base do aprendizado que possibilita ao homem o desenvolvimento das habilidades e capacidades físicas e intelectuais necessárias à formação do novo intelectual, assim como garantem a inserção social e a posterior qualificação profissional. Na perspectiva gramsciana a emancipação não está no acúmulo de conhecimento teórico, mas no domínio do método. É com este fim que o ensino da cultura geral emerge na práxis educativa como um instrumento privilegiado para a transmissão e apropriação dos parâmetros teóricos-metodológicos necessários ao filosofar e à análise da sociedade.

A iniciativa aparece na carta 435 quando, por ocasião da memória do centenário da morte Alexander Puschkin (1799-1837), um clássico da literatura russa, propôs a Delio que desenvolvesse um estudo a partir do seguinte questão: “[...] por que Puschkin, apesar de sua universalidade poética, só é apreciado fora da Rússia por poucos intelectuais, diferentemente de outros artistas russos, que rapidamente conquistaram uma grande popularidade em todo mundo? [...]" (CtC 435, v. 2, p. 396-397). O exercício da pesquisa é utilizado por Gramsci como uma estratégia para que os filhos possam entrar em contato com os métodos de investigação, com o rigor teórico e com a disciplina de estudo.

${ }^{12}$ Gramsci não atribuiu à noção de ideologia o caráter negativo que esta adquiriu em Marx e Engels quando da elaboração da Ideologia Alemã. Uma possível explicação para este fato é decorrente da possibilidade que Gramsci, em função de suas condições excepcionais, não tenha tido acesso a essa obra (LIGUORI, 2007). 
Volume, 14, número, 1, ano, 2018.

Ao propor a pesquisa a partir de um tema de cultura geral, Gramsci estava criando as condições necessárias para o desenvolvimento da capacidade intelectual de Delio. Se na primeira vez que propôs um problema deu logo a resposta, desta vez, limitou-se a apresentar um método que permitiria ao menino solucionar a questão. Ao mencionar o centenário de Puschkin indagou se algum especialista iria à escola falar sobre o tema, está era uma indicação do caminho para a resolução do problema. Ele sabia que a tarefa era difícil, mas a preocupação não estava focada no resultado final, no aprendizado teórico do tema, mas sim no exercício a ser desenvolvido, prática que exigia empenho e dedicação e em decorrência do esforço empreendido o resultado era a aquisição da disciplina de estudo necessária ao desenvolvimento intelectual.

Sem se esforçar demais, peça algumas sugestões e me escreva. Caro Delio, aprecio muito sua inteligência e, por isso, apresento este problema, mas não se esforce demais, afinal... sempre há tempo. Não é uma questão que se resolva com poucas palavras, não é verdade? Mas sei que você também é um grande admirador de Puschkin [...] (CtC 435, v. 2. p. 397).

Pelas cartas da edição brasileira não foi possível identificar se Delio fez a pesquisa sobre Puschkin. Mas, quando o assunto foi mencionado novamente na carta 447, retomando o tema da percepção e julgamento acerca daquilo que é certo ou verdadeiro, Gramsci desafiou Delio a demonstrar sua maturidade intelectual. Com isso, era reestabelecido o equilíbrio entre o desafio e a valorização das condições reais do desenvolvimento físico e intelectual.

Escreva sobre Puschkin quando quiser, aliás, é melhor pensar bastante sobre ele, para que você me de uma prova conclusiva de sua capacidade de pensar, raciocinar e criticar (isto é, de discernir o verdadeiro do falso, o certo do possível e do verossímil). Mas não fique nervoso: eu sei sua idade, sua preparação e, portanto, vou saber julgar objetivamente [...] (CtC 447, v. 2. p. 409).

A carta é finalizada com considerações sobre a atualidade dos estudos sobre Puschkin e as dificuldades de acesso aos textos originais. A reflexão chamava a atenção para o fato de que por ser difícil ter acesso à obra do autor, poucas pessoas conheciam os seus escritos e julgavam seu pensamento pela análise de terceiros, sem operar a leitura direta do texto. 
REVISTAELETRÔNICA

IyHFianims RAF Fiscillonis

Volume, 14, número, 1, ano, 2018.

Tema semelhante foi objeto de diálogo entre Gramsci e Giuliano na carta 434. Aqui também Gramsci incentiva o filho a buscar o domínio da natureza física e intelectual pelo desenvolvimento da disciplina de estudo. Gramsci havia tomado conhecimento do fato de que Giuliano estava apresentado dificuldades nas atividades escolares e questionou-o sobre a natureza dessas dificuldades. Novamente, deu historicidade e materialidade ao problema rememorando sua própria experiência escolar e, mesmo consciente de que à distância não poderia intervir na questão, explorou o assunto nos seguintes termos: “[...] Ficaria muito contente se me explicasse em que consistem as dificuldades que tem encontrado no estudo. Parece-me que, se você mesmo reconhece ter dificuldades, elas não devem ser muito grandes e você pode superá-las com esforço e boa vontade [...]" (CtC 434, v. 2. p. 395).

Gramsci reforça a perspectiva de que para superar as dificuldades da vida intelectual é necessário esforço e dedicação. Não se deve, no entanto, entender levianamente que ele fazia vistas grossas aos problemas de aprendizagem de Giuliano, ou mesmo afirmar que ele era ingênuo e acreditava que os problemas escolares do filho se resolveriam com a simples dedicação do menino. Gramsci procurou fornecer aos filhos a consciência de suas limitações, condição que lhes ajudaria a escolher qual caminho trilhar em sua formação escolar, iniciando com a formação intelectual até atingir a maturidade necessária para a formação profissional, como havia exposto a Delio na carta 437.

$\mathrm{Na}$ carta 446 incentivou Giuliano a escrever sobre os livros que gostava e, provavelmente em decorrência de sua resposta, escreveu na carta 451 uma reflexão semelhante a que havia desenvolvido com Delio sobre Puschkin e a vida de estudos, iniciativa que traz a tona novamente a perspectiva de domínio do método. O tema da carta era a obra de Herbert George Wells (1866-1946) e um julgamento de valor proferido por Giuliano. Gramsci promoveu uma reflexão na qual apresentava ao filho mais novo o mesmo princípio metodológico que apresentara a Delio: era necessário fundamentar os juízos proferidos com base no conhecimento real do fato analisado.

Você só leu metade de uma novela de Wells e já quer julgar toda a obra desse escritor, que escreveu dezenas de romances, coletâneas de novelas, ensaios históricos, etc.? Parece-me 'um pouco exagerado'. E, afinal, que novela você leu? A mais bonita, a mais feia ou a que representa a média das possibilidades do autor? [...] (CtC 446, v. 2. p. 408). 


\section{REVISTA ELETRÔNICA \\ GRADUAÇÃO/PÓS-GRADUAÇÃO EM EDUCAÇÃO \\ UFG/REJ}

ISSN $1807-9342$

Volume, 14, número, 1, ano, 2018.

Os questionamentos levantados por Gramsci apontam as contradições do julgamento de Giuliano sobre a obra de Wells. Por outro lado, revelam o valor e a importância do rigor na hora de proceder uma análise. Eles ainda apontam um caminho, isto é um método a ser posto em prática quando da construção de um julgamento. De certa forma, as questões apresentadas serviam de provocação ou estímulo para Giuliano. Na sequência, dirigindo-se para além da simples reflexão teórica e dando historicidade e materialidade ao diálogo, Gramsci colocou Giuliano no lugar de Wells e aplicou sobre ele sua própria crítica analisando a carta enviada pelo filho. Ao valorizar a disciplina de estudos Gramsci buscava demonstrar que o resultado de um trabalho é decorrente da dedicação de seu realizador e que é característico da produção intelectual submeter os argumentos à reelaborações antes que estes possam ser considerados como definitivos. Junto ao método de estudo, fica evidente a diretriz de que no trabalho intelectual era necessário persistir, recomeçar e reconstruir ${ }^{13}$.

[...] Você também, com frequência, não é organizado: sua carta está escrita de modo apressado, com muitas palavras deixadas pela metade; mas acredito que possa escrever muito melhor, com mais ordem, com mais atenção. Por isso não vou julgá-lo por esta carta [...]. Caro Julik, não me leve a mal escreva sempre tudo o que pensa, mesmo com pressa; depois, você volta a pensar melhor, corrige seus erros e consolida suas opiniões [...] (CtC 451, v. 2, p. 414).

Gramsci valorizava a disciplina e defendia a necessidade de direcionar o processo educativo, pois um processo educativo emancipatório precisa dotar o sujeito de autonomia, por isso a apropriação do método de análise ganha importância. As indicações apresentadas a Giuliano permitem afirmar que Gramsci reconhecia que a coerção nem sempre o melhor caminho e, mesmo solicitando insistentemente a seus filhos que lhe escrevessem, valorizava a autonomia, a escolha pessoal e subjetiva. Na carta a Giuliano de 23 de janeiro de 1937, a questão do método emerge da tensão dialética entre direcionamento e liberdade e se manifesta na consciência que o sujeito tem sobre a própria ação: "Desenhe como quiser, para rir e se divertir, e não 'seriamente', como se fizesse um dever do qual não gosta. Mas gostaria de ver alguns desenhos que tem feito para a escola! Como é que faz esses desenhos? Com seriedade ou, ao contrário, como os que faz de brincadeira? [...]" (CtC 457, v. 2, p. 421).

${ }^{13}$ Cabe ressaltar que, como demontraram Valentino Gerratana (1997) e Giorgio Baratta (2000), este foi o método empregado por Gramsci na redação dos Cadernos do Cárcere. 
REVISTAELETRÔNICA

GRADUAÇÃO /PÓS-GRADUAÇÃO EM EDUCAÇÃ O RaFliscriloris

Volume, 14, número, 1, ano, 2018.

Ao incentivar o filho a desenhar pelo prazer ao mesmo tempo em que demonstrava interesse pelos seus desenhos escolares, Gramsci exercita uma práxis educativa voltada ao desenvolvimento da autonomia e a conquista da emancipação. Ele retoma a questão da formação intelectual e chama atenção para a relação entre o domínio da técnica e do método e o prazer de executar uma atividade. Gramsci não se importava se o filho desenhava por brincadeira ou por obrigação, seu interesse estava na consciência que o menino tinha sobre aquilo que produzia. A pergunta "Como é que faz esses desenhos?" remete a questão metodológica e reforça a perspectiva de que a formação intelectual está relacionada ao domínio do saber-fazer, condição que propicia ao homem os meios para refletir sobre sua própria prática e para elaborar a sua concepção de mundo.

A formação de uma consciência crítica era um elemento constante nas cartas de Gramsci aos filhos, está presente nos diferentes temas de Wells e Puschkin ao conhecimento da natureza e da participação ativa no desenvolvimento industrial do país. A práxis educativa desenvolvida é emancipatória porque opera sobre a conformação dos indivíduos à organização social de seu tempo e almeja que, gradativamente, o sujeito atinja a maturidade intelectual. Em todo este processo Gramsci questionou os filhos e os conduziu por análises sobre o que escreviam e pensavam, promovendo com eles uma espécie de catarse.

$\mathrm{Na}$ carta 459, no entanto, fez uma proposta diferente a Delio: "Diga se você gosta desse meu modo de escrever e se compreende tudo" (CtC 459, v. 2, p. 422). Gramsci estava propondo um novo problema. Um que, para ser resolvido, era necessário por em prática os ensinamentos anteriores: analisar apenas o que estava escrito sem fantasiar, distinguir o que era possível e real ao pai encarcerado e doente e analisar o conteúdo das cartas recebidas; para isso era necessário ser organizado e ter guardado as cartas, julgar o estilo literário e o conteúdo de cada uma, dado que não se podia analisar o livro pela capa ou a obra de um autor pelo conhecimento de uma única novela. Como nas outras vezes em que propôs um problema, Gramsci apresentou a Delio uma solução que, além de retomar todos os temas anteriores, por sua vez, pode ser considerada uma das mais belas passagens das cartas.

[...] Vê-se que, na evolução do homem, juntaram-se muitas condições favoráveis no sentido de ajudá-lo a se tornar o que era, mesmo antes de se desenvolverem a vontade definida para um fim e a inteligência suficiente para organizar os meios necessários para alcançar o próprio fim. Ao que 
Volume, 14, número, 1, ano, 2018.

parece, a quantidade se torna qualidade para o homem e não para os outros seres vivos. Escreva-me muito (CtC 459, v. 2, p. 423).

A passagem historiciza e fornece materialidade à concepção gramsciana de educação. O processo de desenvolvimento humano possibilitado pelas condições materiais que se fizeram favoráveis, somados a sagacidade do homem ao dominar sua própria natureza e colocá-la ao seu dispor, enceram em si a formação histórica do homem e o caminho para sua emancipação. Essa formação é mediada pela disciplina que permitiu ao homem direcionar sua vontade para um fim que é alcançado mediante a insistência constante, que transforma a repetição em perfeição. Esse é o espírito da correspondência entre Gramsci e seus filhos. A solicitação apresentada ao final da carta atualiza toda a análise histórica realizada por Gramsci ao direcionar o processo de formação humana para seus filhos de maneira concreta e real em um simples "Escreva-me muito". Essa é a tônica de toda a sua correspondência com os filhos e um dos elementos mais sagazes da práxis educativa proposta nos Cadernos.

Em todo o conjunto das correspondências Gramsci repete a frase, "Escreva-me muito". Ainda que nesse pedido estivesse contido o anseio de um pai por notícias de seus filhos, ela representa a chave do processo de formação humana, a ação que se transforma em consciência sobre o próprio agir e que permite ao homem se reconstruir, reorganizar e refazer de modo consciente e disciplinado. O desenvolvimento das habilidades intelectuais e o domínio do método permitem ao homem avançar para um novo estágio de compreensão da realidade e é isso que Gramsci propôs aos filhos em uma nova fase de reflexão. Na carta 464 convida Delio para o estudo da história real dos homens, do fato real, concreto e calcado na materialidade da vida. Se escrever com qualidade era resultado da prática disciplinada, do domínio da escrita e de suas peculiaridades, Gramsci vai indicar que o estudo da história era constituído sobre os fatos, livres da especulação fundamentada na fantasia.

[...] Você me escreveu que gostava de história [...]. Acredito que para estudar a história, não se deve fantasiar muito sobre o que teria acontecido, se... [...] Já é muito difícil estudar a história realmente acontecida, porque se perdeu todo e qualquer documento de grande parte dela; como se pode perder tempo estabelecendo hipóteses que não tem fundamento? [...] (CtC 464, v. 2, p. 426). 
Volume, 14, número, 1, ano, 2018.

Superar a fantasia e se ater à realidade é um elementos chave da análise de Gramsci sobre a filosofia apresentada nos Cadernos 10 e 11 . Análise que se volta para a formação da consciência política e cultural dos trabalhadores e desencadeia um movimento de construção da filosofia da práxis. A elaboração da filosofia da práxis estava condicionada à educação dos proletários e essa, por sua vez, a todos os momentos da formação intelectual que Gramsci apresentou aos filhos. Em síntese os ensinamentos de Gramsci aos seus filhos representam a fórmula para a emancipação humana, ou, em termos mais reais, a fórmula para a libertação do homem do jugo imposto pela sociedade industrial e sua cultura de conformação do trabalhador. É o momento catártico pelo qual o homem supera o momento meramente econômico, egoístico e passional, para caminhar em direção à reforma intelectual e moral. Em outras palavras é a famosa passagem do reino da necessidade para o reino da liberdade.

O valor da história como ponto de partida para as novas reflexões foi apresentado a Delio, que era instigado a superar a fantasia e se debruçar sobre o mundo real, sobre as transformações que estavam ocorrendo na sociedade. Delio e Giuliano participavam de um sistema escolar regular e recebiam uma educação fundamentada em princípios ideológicos precisos que, na opinião de Gramsci, precisavam ser superados. Ele tinha consciência dos limites do sistema educacional que seus filhos frequentavam e, talvez por isso, tenha escrito a Delio que sua forma de pensar estava ultrapassada e limitada a uma concepção de ciência que não representava mais a realidade mas a um modelo histórico que lhe sustentava e havia dado lugar a outra forma de ver e entender o mundo.

[...] seria mais oportuno estudar a história real, aquela que se pode escrever com base em documentos bem precisos e concretos. Fantasiar sobre hipóteses científicas era típico de homens que, há cinqüenta anos, viviam em condições muito difíceis de luta ideológica. Hoje, muitas questões caíram no vazio porque a vida superou tanto o protagonista quanto o antagonista e criou o construtor [...] (CtC 465, v. 2, p. 427).

Gramsci escrevia aos filhos como pai, afastado da realidade e condicionado a rotina desgastante da vida carcerária. Não tinha muitas perspectivas de ver Delio novamente e de finalmente conhecer Giuliano pessoalmente. Mas ao longo dos anos em que escreveu as limitadas linhas que compõe o conjunto das cartas aos seus filhos, produziu uma práxis educativa interessante, fundamentada na reflexão sobre a formação humana, sobre o 
REVISTA ELETRÔNICA

GRADUAÇÃO/PÓS-GRADUAÇÃO EM EDUCAÇÃO REFLECTIONIS

Volume, 14, número, 1, ano, 2018.

desenvolvimento do homem e sobre os princípios fundamentais necessários ao desenvolvimento intelectual das novas gerações. O valor educativo das cartas aos filhos não está na teorização de um modelo educacional, mas na vivacidade e na vitalidade de uma práxis educativa da forma e materialidade a concepção gramsciana de educação e de organização escolar.

\section{CONCLUSÃO}

Gramsci escreveu aos filhos 43 cartas. Nelas desenvolveu uma práxis educativa emancipatória, mesmo diante das adversidades impostas pela vida carcerária. No diálogo com os filhos e a partir de diferentes temas extraídos do cotidiano de Delio e Giuliano desenvolveu um amplo trabalho de formação intelectual, no qual enfatizou o valor e a importância da disciplina de estudos e da apropriação do método. Por suas reflexões indicava aos filhos que eles faziam parte de uma realidade complexa e participavam de um processo histórico de formação que extrapolava a realidade imediata da qual faziam parte.

Embora não faça menção as notas dos Cadernos do Cárcere, as reflexões que desenvolveu com os filhos tangenciam e retomam as concepções que teorizou e defendeu. Os temas explorados fazem emergir a noção de emancipação humana e remetem a questões como a formação dos intelectuais e suas relações com os grupos dirigentes, a noção de trabalho como princípio educativo, a concepção de escola unitária e a elaboração da filosofia da práxis a partir da qual o homem toma consciência de si e do mundo em que vive. Temas que se materializam em uma práxis educativa que orientava Delio e Giuliano na conquista da autonomia intelectual.

Pelas atividades que propôs aos seus filhos, Gramsci fornece um indicativo de que suas formulações nos cadernos devem sair da teorização e se tornarem um projeto de ação com vistas a uma práxis educativa emancipatória. Para isso, orientou os filhos, e por meio deles as novas gerações dos grupos sociais subalternos, no desenvolvimento das habilidades físicas e intelectuais necessárias a conquista da emancipação, primando pela aquisição da disciplina de estudos, pela responsabilidade e persistência, pelo domínio do método e pelo respeito aos limites pessoais de cada um. Incentivou o pensamento e a reflexão sobre a própria prática e a não produzir julgamentos sem a devida fundamentação, evidenciando que 


\section{Hyltianimus RBFliscilloils \\ REVISTA ELETRÔNICA \\ GRADUAÇÃ O/PÓS-GRADUAÇÃO EM EDUCAÇÃ O \\ UFG/REJ}

ISSN $1807-9342$

Volume, 14, número, 1, ano, 2018.

ter ideias próprias era uma conquista de longo prazo e que para comunicá-las com perfeição era necessário submetê-las a reformulações fundamentadas na realidade, na análise dos fatos históricos. Essas indicações, características da práxis educativa gramsciana, visam transformação da realidade, uma vez que pela educação o homem é capaz de dominar a própria natureza e se tornar um homem atual, o homem de cada tempo histórico.

\section{REFERÊNCIAS}

ARNAUT DE TOLEDO, Cézar de Alencar; GOMES, Jarbas Mauricio. Antonio Gramsci e a organização da escola italiana (1922-1932). Revista Diálogo Educacional. Curitiba, v. 13, n. 40, p. 1105-1120, set./Dez. 2013.

BARATTA, Giorgio. Le rose e i quaderni: saggio sul pensiero di Antonio Gramsci. Roma: Gambaretti Editrice, 2000.

FIORI, Giuseppe. A vida de Antonio Gramsci. Tradução de Sergio Lamarão. Rio de Janeiro: Paz e Terra, 1979.

HENRIQUES, Luis Sérgio. Introdução. In: GRAMSCI, Antonio. Cartas do Cárcere Volume 1. Tradução de Luiz Sérgio Henriques; Organização de Carlos Nelson Coutinho e Luiz Sérgio Henriques. Rio de Janeiro: Civilização Brasileira, 2005. p. 7-46.

GERRATANA, Valentino. Gramsci: problemi di metodo. Roma: Editori Riuniti, 1997.

GRAMSCI, Antonio. Cadernos do Cárcere, Volume 2: Os Intelectuais. O Princípio Educativo. Jornalismo. 4 ed. Tradução de Carlos Nelson Coutinho. Co-edição de Luiz Sérgio Henriques e Marco Aurélio Nogueira. Rio de Janeiro: Civilização Brasileira, 2006.

. Cartas do Cárcere, Volume 1: 1926-1930. Tradução de Luiz Sérgio Henriques;

Organização de Carlos Nelson Coutinho e Luiz Sérgio Henriques. Rio de Janeiro: Civilização Brasileira, 2005.

Cartas do Cárcere, Volume 2: 1931-1937. Tradução de Luiz Sérgio Henriques; Organização de Carlos Nelson Coutinho e Luiz Sérgio Henriques. Rio de Janeiro: Civilização Brasileira, 2005.

. Antonio Gramsci ai figli. Roma: Camera dei Deputati, 2007. Disponível em: <http://fondazione.camera.it/sites/default/files/6-antonio_gramsci_ai_figli_lettere_dal_ carcere.pdf $>$. Acesso em 5 jul 2013.

Lettere dal carcere. A cura de Paolo Spriano.Torino: Einaudi, 1971. 


\section{REVISTA ELETRÔNICA \\ GRADUAÇ ÃO/PÓS-GRADUAÇÃO E M EDUCAÇ, ÃO UFG/REJ}

Volume, 14, número, 1, ano, 2018.

Os Intelectuais e a Organização da Cultura. Tradução de Carlos Nelson Coutinho.

Rio de Janeiro: Civilização Brasileira, 1982.

Quaderni del Carcere. Edizione crittica dell'Istituto Gramsci a cura di Valentino Gerratana. Torino: Einaudi, 2007. 4v.

LIGUORI, Guido. Roteiros para Gramsci. Trad. Luiz Sérgio Henriques. Rio de Janeiro: UFRJ, 2007.

MANACORDA, Mario Alighiero. O princípio educativo em Gramsci: americanismo e conformismo. 2. ed. brasileira. Tradução de Willian Lagos. Campinas: Alínea, 2008.

MELO, Alessandro de; HEIJMANS, Rosemary Dore. A educação de Edmea: concepções educativas de Gramsci nas Cartas do Cárcere. Revista HISTEDBR On-line. Campinas, n. 54, p. 41-53, Dez. 2013.

NOSELLA, Paolo. A escola de Gramsci. 3. ed. rev. e atual. São Paulo: Cortez, 2004.

VACCA, Giuseppe. Appunti su Togliatti editore delle "Lettere" e dei "Quaderni". Studi Storici. Anno 31, n. 3, Jul/Set. 1991. p. 639-662.

Sraffa come fonte di notizie per la biografia di Gramsci. Studi Storici. Anno 40, $n$. 1, Jan/Mar. 1999. p.5-37.

ZANEDIM, Ana Priscila Cardoso; MELO, Alessandro de. Princípio educativo nas Cartas do Cárcere de Antonio Gramsci. In: GONÇALVES JUNIOR, Ernando Brito (Org.). Educação em perspectiva crítica: inquietudes, análises e experiências. Curitiba: Appris, 2016. p. 39-64. 